Operation performed in sixth week following confinement. Two days before operation her temperature was $103^{\circ} \mathrm{F}$, pulse 130. A thorough purging in preparing her for the operation reduced her temperature the day before the operation to $99^{\circ} \mathrm{F}$. On morning of the operation her temperature was $97^{\circ} \mathbf{F}$., pulse 130 , an unfavorable condition it is true, for an operation, but bid fair to be the best I was likely to find her in.

At the operation I found as I had predicted, many firm inflammatory bands binding down the uterus, matting together the intestines, omentum and tubes. The uterus was firm and about the size one would expect to find five weeks after delivery. The ovaries and tubes on the right side were filled with pus and firmly bound down under the uterus; the left tube was likewise distended with pus; there was nothing left of the left ovary but a cheesy disorganized mass. The adhesions were broken up, sound organs liberated and diseased structures removed, the peritoneum irrigated, and glass drainage tube introduced. Entire time of operation thirty minutes. The patient reacted nicely and bid fair for fortyeight hours to recover. At this time her heart gave out and my patient died-not from an extension or rekindling of the peritonitis, but from exhaustion induced by her long illness prior to the operation.

Every puerperal woman developing a fever does not necessarily imply that a laparotomy is the only resort, but it does signify that she has somewhere a cause for the fever and that the focus of absorption is in the genital tract in the majority of cases. The variety or location in this tract should point out the proper treatment.

This case was operated on since this article was read. I now add it to the above report.

Case 2.-Puerperal Sepsis. - Laparotomy.-Recovery. - This lady two or three days after labor developed a "puerperal fever," having suffered much in region of right ovary during the last few months of her pregnancy. When I saw her two weeks after confinement she was having a septic fever, with much pain in pelvis. Examination revealed a"boggy"mass to right of uterus extending to a level with the anterior superior spinous process. This examination was made two weeks after labor. She was septic, temperature running from subnormal to $104^{\circ} \mathrm{F}$, pulse from 110 to 140 .

Operation revealed the true character of the mass to right of uterus ; omentum, bowel, fallopian tube and ovary all matted together. The tube was cheesy and disorganized, showing well marked evidence of long pathological changes. Sound organs liberated and diseased structures, removed, gallons of hot sterilized water used with irrigator, drainage and recovery.

This was certainly a case of autogenetic puerperal infection. That the woman was septic, as much as any one could be and live, is beyond doubt.

The right fallopian tube and its contents were responsible for the attack.

DEDUCTIONS.

1. Many cases of puerperal sepsis develop regardless of any aseptic precautions on the part of the accoucheur. In the majority of cases in this type of the disease the foci of infection will be found in the fallopian tubes.

2. Fallopian tubes may be infected with the gonococci, or other specific or pathogenic bacteria after impregnation.

3. Pathogenic microörganisms develop more rapidly and are more virulent during the puerperal period. This is due to the fact that (either) the secretions are more favorable culture fluids or there exists a weakening of the resisting powers (want of immunity) on the part of the lying-in woman.

4. Rely upon the physical examination of the case under investigation in classifying the form of the disease you have to deal with.

5. After deciding as to the location of the poisonous foci, the treatment at once suggests itself.
6. If in doubt as to the source begin with the milder procedure and watch closely the results of your treatment. If permanent improvement does not soon take place direct your course in another direction. Sur. gery in these cases must be done early, thoroughly and quickly to insure the lowest rate of mortality. Delayed and imperfect work will, in these cases, always bring disastrous results.

Rialto Building.

\section{CONTAGIOUSNESS OF CONSUMPTION.}

Read before, and unanimously endorsed by, the Medical Association of Georgia, April 20, 1893.

BY J. G. HOPKINS, M.D.,

OF THOMASVILLE, GA.

The question as to whether consumption is contagious or not is one of vital importance to posterity as well as to the present generation. While the theory of Koch is becoming generally accepted, there are still many who are skeptical upon the subject. These skeptics, in a great measure, are confined to those who have not given the work of Koch and his collaborators much of their time or attention. They look upon the bacillus as septic or putrefactive rather than pathogenic. I have joined that growing army which places tuberculosis in the category of contagious diseases, and my experience with this disease during nineteen years of investigation in Thomasville, which place is a resort for consumptives, bears me out in my opinion and makes me a willing subject of the great and erudite Koch. I do not intend, in this article, to delve in the depths of science by entering into minutiæ, but simply to deal with facts as we find them.

We will take, to begin with, the negro, a creature in whom, prior to and during the war between the States, consumption was unheard of. In those days he was properly fed, properly clad, kept out of doors in the day time, was never crowded, and rest at night was compulsory. This process kept him, as far as possible, up to the "norm," and he was better enabled to wrestle with such disease germs as may have invaded his person. There is a vast contrast between then and now; his environments are materially changed, as any resident of, or sojourner in the South can testify. It is a well known fact, as shown by the records of our sexton, that more negroes die of consumption in Thomasville since the place has been a resort than ever before, and we find also that most of those who die of it have been at some time or other connected with some hotel or boardinghonse in the capacity of chambermaid, laundress, or some other which exposed them more than others to the invasion of the tubercle bacillus. It is true that the whites escape to a far greater extent than the blacks, but it is also true that they are not as intimately connected with these subjects, and it is a well known fact that the whites possess far greater powers of resisting disease than the negro-except those of malaria and syphilis. We see this exemplified more particularly in diseases of the air passages. The percentage of recovery from pneumonia is so small that it is rave for a negro to recover from a severe case of the disease.

Frequently we find that the wife of a consumptive husband, or vice versa, comes down also with consumption, and dies as did the loved companion of life. Many instances of this character could be 
mentioned in which it was impossible to trace any family taint whatever in the subject last to succumb to the disease, the one evidently contracting it from the other. We may and do inherit color of hair, eyes and many family characteristics, and we do also inherit conditions of lungs and throats which supply proper pabulum for sustenance and afford ample culture fields for the propagation of the tubercle bacillus, hence we frequently find that more than one member of the same family dies of consumption.

I do not doubt but that all men, women and children at some time or times receive into their air passages the tubercle bacilli, but fortunately the great majority possess the power of repelling them and throwing them off. They do not find that soil, so to speak, which is adapted to their growth. As we find in our fields soil within which certain grain will germinate and reproduce its kind, and other again upon which the same grain would fail to germinate, or if it did germinate would spring up but to wither and die for want of sustenance; just so we find birds, quadrupeds and persons in whom the tubercle bacillus will find ample conditions for its reproduction; others in whom this pabulum is entirely wanting; and others again in whom it is so scantily found that the bacillus, after struggling for existence for a time, is cast off, leaving the subject to regain as good health as before the invasion.

Most of the caged animals die of consumption, and the anti-contagionist would say it is because of environment. I admit that environment plays a conspicuous part in the propagation of this disease, but numerous experiments upon animals have shown conclusively that there must be more than this. Trudeau subjected a number of rabbits to similar conditions-those of confinement in damp dark places, scanty sustenance, etc., half of which number he inoculated with tubercle bacilli, and separated them from the rest; within four months all of those inoculated but one had died of consumption, and this one being killed was found to have a well developed case of it. At the expiration of the fourth month all of those not inoculated were killed, not one having died, and the most searching autopsy failed to reveal the slightest evidence of disease in a single one of them. The same number of inoculated rabbits were now turned loose on an island. They were in their native element and well fed; freedom, sunlight and all conditions conducive to health were provided. Only one of them died of consumption, while at the end of four months the remainder were by autopsy proven to be in a state of perfect physical condition.

Animals confined in museums are not only subjected to an unnatural life, but to the filth and foul odors of their cages, the dampness resulting from washing out these cages, and exclusion of sunlight, all of which are strong factors in lowering vital energy, but are hourly exposed to the tubercle bacilli, which are spat about the building and often even in the cages themselves, by the consumptive spectator, who unwittingly scatters these germs of destruction broadcast as he passes by with the eager throng of lookers on. One animal may yield to the invasion, and it is not discovered until he has impregnated that cage with germs enough to destroy every animal ever put into it, for they are passed from one to another, and will be throughout eternity, unless proper action can be taken to prevent it. These creatures in their native state never die of consumption.
Roaming the wilds at will, with no shelter but the broad canopy of heaven, and warmed into animation by the glorious sunlight, that mighty destroyer of germ life, they are placed beyond the ravages of the tubercle bacillus. Just so it is with the higher order of animals.

Indians in a state of nativity seem impervious to the germs of consumption, but are now dying by thousands on the reservations. The whites and the blacks in prisons and asylums all over the world, labor under similar conditions. A report from the Illinois State Prison at Joliet says:

"There are fourteen hundred convicts within the walls, and fully one-third of them have consumption in a light or bad form. Nearly all deaths of persons in the penitentiary have been caused by consumption, and as a rule, all long termers either die within the walls from the disease or are pardoned out on account of it."

The percentage of mortality from consumption at the Georgia Lunatic Asylum is $39 \frac{6}{7} \frac{3}{6}$ per cent., and in other asylums and prisons it is much the same. In States where the "farming" system with convicts exists, this condition of things does not obtain. Statistics from the Georgia convict camps collected and published by my father, Dr. T. S. Hopkins, show that out of 2,803 convicts farmed out in various sections of the State between Oct. 1, 1890 and Oct. 1, 1892 , covering a period of two years, there were only nineteen deaths from consumption, making a mortality of $3 \frac{63}{100}$ per cent. Now being in possession of these facts, convincing as they are, that environment plays a prominent part in the propagation of the disease, is there wisdom in congregating those already diseased, or herding together the sick and the well? There is no doubt in my mind that danger lurks in sleeping cars, in carpets, bedding, clothing and in the walls of apartments occupied by consumptives, which have not been properly renovated and rendered innocuous by antiseptic measures, and if it were not for the fact, as I believe, that the direct rays of the sun will destroy this bacillus, the inhabitants of consumptive resorts would be in far greater danger than they are from the myriads of them that are daily spat upon the streets. It is a known fact that the more nearly we approach the original man in our habits of life, the more exempt we are from disease; hence, it is apparent that isolation in the cottage system in a section of country as nearly "aseptic because it is antiseptic," as we can find, coupled with an observance of antiseptic laws will afford the most fruitful source of relief to the pulmonary invalid, and do most toward preventing contagion.

Hundreds of years have been spent in searching for a remedy which would-successfully baffle this fell destroyer, whose ruthless clutches drag annually from America to eternity one hundred thousand souls, and still the search goes on. Each year serves but to convince us more fully that from drugs but little can be expected, and we can but continue, as has been done ever since the beginning of the art of medicine, to try the efficacy of climate. Ever since the days of Hippocrates, consumptives have been sent to the pine forests, as they are to-day. That the bacillus is often rendered inactive and an arrest in the progress of the disease induced by a sojourn in these pine sections is evidenced by ample proof, but how much more could we expect if these cases were 
scattered through the country in cottages rather than massed in the cities and towns in crowded hotels, where they are dependent, for a part of the time at least, upon oxygen abstracted from air polluted by excretions and exhalations from the bodies of other invalids, and they themselves adding to the fruitful source of contamination.

Consumptives should be forced to provide for the destruction of sputa. Whenever situated so as not to expectorate directly into a germicide or the fire, they should use some means of conveying the sputa to the germicide or the flames. If handkerchiefs or cloths be used they should not be sent to the laundry as human happiness and life are jeopardized through the probability of inoculation through abrasions upon the hands. These bacilli should never be allowed to dry up and impregnate the air, as is now done through ignorance of possible results. Numerous experiments by leading medical authorities have proven beyond doubt that consumption is an inoculable disease, and so rapidly is the throng of converts growing that I would not be surprised if, even in my day, resorts now soliciting the patronage of the consumptive, will be quarantining against him.

\section{TUMORS OF THE BLADDER.}

Read by Invitation before the Wisconsin State Medical Society, May 5 . 1893.

BY JOHN B. HAMILTON, M.D., LI.D.,

PROPESSOR PRINCTPLES OF SURGERY AND CLINFCAL SURGERY, RUSH MEDICAL COLLEGE, CHICAGO; PROFESSOR OF SURGERY, CHICAGO POLICLINIC; SURGEON, FOBMERLY SUPERVISING SURGEONGENERAI U. S. MARINE-HOSPITAI SERVICE, ETC.

HISTORY.

The literature of the subject of tumors of the bladder is almost wholly modern. The ancients had a lively sense of the dangers of meddlesome interference with the bladder and although the operation of stone crushing has probably been known from the earliest times it is only since the day of Civiale and Leroy d'Etiolles that tumors of the bladder began to be commonly extirpated. According to Tuffier ${ }^{1}$, Varner in 1750 removed a vesical polypus, but no details of the case are given. The silence on the subject is the more remarkable when we consider that instead of being infrequent among other affections of the bladder tumors are common. Sir Henry Thompson, than whom there has been no higher modern authority, relates that in November, 1880 , he practiced exploratory incision in the urethra for a case which he was unable to diagnose by the methods then adopted; "most unexpectedly," he says, he found a polypoid tumor. Subsequently, in thirty out of eighty cases of digital exploration of the bladder, Sir Henry found tumor.

\section{ETIOLOGY AND PATHOLOGY.}

The causes of vesical neoplasms are very obscure, but indeed the same general observation may be made regarding tumors elsewhere. The law of Müller that all tumors consist of some tissue-type previously existing in the body holds true here as elsewhere. The tumors commonly met with in the bladder, are of the two general characteristics, malignant and non-malignant.

The malignant tumors are:

Sarcomata.

Carcinomata.
To these may be fairly added Tuberculosis, if we could forget that Tuberculosis is a degeneration rather than a neoplasm. The nomenclature of the Royal College of Physicians and Surgeons still classes Tuberculosis among the tumors.

The non-malignant tumors are classed by Barling: Papillomata, Fibro-Fimbriated.

Fibromata.

Fibro-Myxoma.

Myxoma.

Adenoma.

Angeioma.

Enchondroma.

Dermoid Cyst.

Hydatid.

Watson (Int. Clinic, Oct. 1891) notes a fact remotely bearing upon causation, that (1.) Males are affected more than twice as often as females; (2.) Excepting myxoma all forms of bladder tumor occur more frequently after thirty-five and carcinoma more frequently after fifty.

Concerning the site of these tumors, Tuffier quotes Guyon as stating that on examination he found that the tumor originated as follows:

At the orifice of the right ureter 45 times per 100 .

At the orifice of the left ureter 26 times per 100 .

In the interspace between the ureters 10 times per 100.

The remainder were variously dispersed.

This corresponds well with Gilbert Barling's statement after inquiry into 260 cases, that two-thirds of the bladder tumors are found springing from the base. Barling is of opinion that certain of the unusual tumors occurring in the bladder, such as the dermoid cysts, may originate in the adjacent tissues and gradually make their way into the bladder. ${ }^{2}$ He asserts that fibromata usually spring from the neck of the bladder or orifice of the ureter. It is of course known to general pathologists that fibromata must come from the connective tissue; they could not spring from the mucous structure.

The site of the myxoma while usually at the base of the bladder is not so constant.

In seventy-four cases of papilloma Barling found eleven commenced near the right ureter, and two near the left. These statistics corroborate those of Fenwick made to the Pathological Society of London in 1889 , where he also asserted that the male was affected three times as often as the female, as shown in a series of 634 cases. Sixty per cent. of the cases were simple; of the single, 43 per cent. sprang from the orifice of the right ureter, to 26 per cent. from the left. Eighty-six per cent. of these growths were at the inferior zone originating at the margins of the trigone, pedunculated wholly or partially in proportion two to one; nobody has as yet vouchsafed a conjecture as to the reason for this curious fact, but the nearly constant proportion of two to one springing from the orifice of the right ureter in preference to the left, shows that some law, not accident, determines this matter.

The external shape of bladder tumors is very variable, the benign tumors having generally broad bases, and fringed or are polypiform, while the malign tumors are generally spread out, and irregular on their surface. In early cases of tuberculosis of the bladder I have often found irregularity of the surface, even where the mucous lining was as

\footnotetext{
2 Birmingham Med. Review, Aug., 1892, et sequitur.
} 